\title{
Distrito SANitário EsPecial IndíGENa do Maranhão: Crônicas de UM DESASTRE ANUNCIADO
}

\author{
INDIGENOUS SPECIAL SANITARY DISTRICT OF MARANHÃO: \\ CHRONICLES OF AN ANNOUNCED DISASTER
}

\author{
István van Deursen Varga ${ }^{(*)}$ \\ Rosana Lima Viana ${ }^{(*)}$
}

\section{RESUMO}

Este trabalho discute a trajetória das políticas e práticas de saúde voltadas aos povos e comunidades indígenas no Maranhão, no âmbito do Distrito Sanitário Especial Indígena do Maranhão (DSEI-MA), da Fundação Nacional de Saúde (FUNASA). As informações apresentadas demonstram que as sucessivas gestões da FUNASA, tanto em seu Departamento de Saúde Indígena (DESAI), em Brasília, como em sua Coordenação Regional do Maranhão (CR-MA) e no próprio DSEI-MA, têm oferecido, de modo geral, resistências à adoção de metodologias efetivamente participativas e à consolidação das instâncias de controle social definidas pelas Conferências Nacionais de Saúde, resultando numa cultura institucional amplamente refratária a propostas que reforcem a capacidade de mobilização e de organização autônomas das comunidades indígenas.

(*) PhD em Saúde Pública, professor adjunto do Departamento de Sociologia e Antropologia e do Programa de Pós-Graduação em Saúde e Ambiente da Universidade Federal do Maranhão (UFMA); coordenador do Programa de Pós-Graduação em Saúde e Ambiente da UFMA; coordenador do Núcleo de extensão e pesquisa com comunidades rurais, negras quilombolas e indígenas da UFMA; líder do Núcleo de Etnologia e Indigenismo da UFMA; pesquisador do Núcleo de Patologia Tropical e Medicina Social da UFMA; pesquisador do grupo de pesquisa Sociedade Contemporânea, Ciências Sociais e Saúde Pública da Faculdade de Saúde Pública da Universidade de São Paulo (USP). E-mail:<ivarga@uol.com.br>.

$\left({ }^{* *}\right)$ Engenheira Sanitarista, mestre em Saúde Pública pela Fundação Oswaldo Cruz - Escola Nacional de Saúde Pública. E-mail:<fragmentosbr@yahoo.com.br>. Recebido em 12.08.08. Aprovado em 30.09.08. 


\section{Palavras-chave}

FUNASA; Maranhão; Políticas Públicas; Saúde Indígena.

\section{ABSTRACT}

This work discuss the trajectories of health attention policies and practices to indigenous communities of the Distrito Sanitário Especial Indígena do Maranhão (DSEI-MA), of Fundação Nacional de Saúde (FUNASA). Informations presented demonstrates that FUNASA's administrations, in Departamento de Saúde Indígena (DESAI), in Brasília, in Coordenação Regional do Maranhão (CR-MA) and in DSEI-MA, has resisted to adopt real participative methodologies and to consolidate social control instruments stated by the National Health Conferences. This situation results in an institutional culture widely adverse to proposals which strenghten the capacity of mobilization and organization of the indigenous communities.

\section{Keywords}

FUNASA; Indigenous Health; Maranhão; Public Politics.

\section{INTRODUÇÃO}

\section{Antecedentes do processo de implantação do Distrito Sanitário Especial Indígena do Maranhão (DSEI-MA)}

A implantação do Distrito Sanitário Especial Indígena do Maranhão (DSEIMA) deu-se em 1999, como a da maior parte dos demais 33 DSEls no país.

A Fundação Nacional de Saúde (FUNASA)/Coordenação Regional do Maranhão (CR-MA), já em 1996, entretanto, incorporou vários profissionais da Fundação Nacional do Índio (FUNAI)/Administração Regional de São Luís (ADR-São Luís) que, mantendo o vínculo (funcional e político) com seu órgão de origem, tiveram seu exercício transferido para a então denominada Equipe de Saúde do Índio (ESAI) da FUNASA/CR-MA, onde tornaram-se, assim, majoritários e hegemônicos, ainda antes da incorporação dos quadros de saúde da FUNAI, determinada pela Portaria Conjunta n. 1 das Presidências da FUNASA e da FUNAI, de 25.8.99(1).

(1) São desse período, dentre outras irregularidades, as compras de grandes lotes dos ditos "protetores hepáticos" (Legalon) pela FUNASA/CR-MA, atendendo às solicitações da Fundação 
Em dezembro de 1998, o Diretor do Departamento de Operações (DEOPE) da FUNASA propôs que se estabelecesse uma parceria com o Mestrado em Saúde e Ambiente (MSA) da Universidade Federal do Maranhão (UFMA), para a elaboração e execução de um projeto conjunto de distritalização dos serviços de saúde para os povos indígenas de todo o estado, que contaria com recursos da então Companhia Vale do Rio Doce (CVRD).

Ficou acordado que, a partir de então, ambas as instituições (a FUNASA, representada pela ESAI, sob assessoria de consultora do DEOPE e a UFMA, por uma equipe que, ao final do processo, contava com 30 docentes, pesquisadores e colaboradores, sob coordenação do Coordenador do Mestrado em Saúde e Ambiente) passariam a elaborar suas respectivas propostas, a serem mutuamente encaminhadas para estudos por suas equipes que, numa terceira etapa, reunir-se-iam para troca de sugestões e elaboração da proposta conjunta.

Em 11 de janeiro de 1999, conforme combinado, a equipe da UFMA encaminhou suas propostas à FUNASA; mas a equipe da FUNASA não fez 0 mesmo. Ao contrário, incorporou o que lhe pareceu interessante na proposta da UFMA e, sem discussão com sua equipe ${ }^{(2)}$, elaborou rapidamente um projeto e o encaminhou à CVRD, ainda em janeiro de 1999, no qual constavam os nomes de alguns professores da UFMA como seus co-autores ${ }^{(3)}$.

O MSA/UFMA, no entanto, só foi informado desses encaminhamentos em contatos com representantes da CVRD, ocasião em que, pela primeira vez, manifestou pública estranheza e divergências em relação à conduta da equipe da FUNASA/CR-MA/ESAI e do DEOPE, no Maranhão.

Em 11 de fevereiro, a equipe da UFMA concluiu a versão definitiva de sua proposta, intitulada "Distrito Sanitário dos Povos Indígenas do Maranhão: projeto de implantação".

Em 11 de março, tendo o Diretor do DEOPE admitido o encaminhamento do projeto à CVRD, sem que sequer a equipe da UFMA tivesse tido vistas do mesmo, o MSA/UFMA enviou-Ihe fax, reiterando publicamente estranheza e várias discordâncias quanto à maneira como o processo vinha sendo conduzido.

Nacional do Índio (FUNAI) e às orientações de seus agentes na ESAI, para os usos duvidosos (do ponto de vista técnico - cf. VARGA, István van Deursen. Educação em saúde: ideologias, racionalidades, discursos e práticas institucionais em 15 anos de indigenismo (Brasil, anos 1980-1995). In: ASSIS, E. (Org.). Educação Indígena na Amazônia: experiências e perspectivas. Belém: Associação de Universidades Amazônicas; Universidade Federal do Pará, 1996. p. 229-269), a maneira do que ocorrera durante o convênio Companhia Vale do Rio Doce (CVRD)-FUNAI, rescindido pela CVRD por indícios de desvio de recursos e medicamentos.

(2) A equipe da FUNASA chegou a tentar fazer discussões em separado com alguns membros da equipe da UFMA.

(3) FUNDAÇÃO NACIONAL DE SAÚDE/COORDENAÇÃO REGIONAL DO MARANHÃO. Distrito Sanitário Especial Indígena do Maranhão. São Luís, 1999. Mimeo. 
Em resposta à missiva da UFMA, o Diretor do DEOPE desculpou-se pelo que descreveu como "falhas na comunicação com sua secretária" (sic), motivo pelo qual a equipe da UFMA ainda não teria recebido cópia do referido projeto. Assim, uma cópia da proposta da FUNASA foi encaminhada à equipe da UFMA.

As discussões a respeito foram retomadas no âmbito da UFMA e, em 16 de março, o MSA/UFMA encaminhou, a todas instituições envolvidas, documento com a versão definitiva da proposta da UFMA ${ }^{(4)}$.

De 28 de março $1^{\circ}$ de abril a FUNASA realizou, em São Luís, seminário sobre sua proposta de implantação do DSEI-MA. A organização do evento foi centralizada pela ESAI e pelo DEOPE e não foram convidadas as organizações indígenas mais preparadas para contribuir nessa discussão, entre as quais o Conselho de Saúde Indígena do Arame (CSIA), a Wyty Catë (Associação das Comunidades Timbira do Maranhão e Tocantins) e a AMTAPAMA (Associação dos Povos Indígenas Tupi de Mato Grosso, Amapá, Pará e Maranhão).

Diante da unanimidade da plenária (da qual participaram docentes da UFMA, entre os quais, o Coordenador do MSA/UFMA) quanto à necessidade de se garantir uma ampla participação das comunidades indígenas nessa discussão, o que ainda não havia ocorrido, acordou-se que a FUNASA tomaria as medidas necessárias para custear o processo, cujo planejamento deveria envolver as demais instituições e representantes indígenas ali presentes.

Para não deixar dúvidas quanto a essas determinações, os índios presentes subscreveram um abaixo-assinado (27 assinaturas) $)^{(5)}$, solicitando anulação de qualquer decisão e encaminhamento em relação ao DSEI-MA, tomado com base naquele evento, sem ampla discussão com as comunidades.

Em 14 de maio de 1999, o MSA/UFMA divulgou o documento intitulado "Projeto Distrito Sanitário Especial Indígena do Maranhão (Ministério da Saúde/Fundação Nacional de Saúde — São Luís, jan./1999): Roteiro e subsídios para discussão", que sintetizava as posições e críticas da equipe da UFMA sobre o processo, tendo por referência as determinações do I Fórum Nacional de Saúde Indígena (I FNSI) e da II Conferência Nacional de Saúde para os Povos Indígenas (II CNSPI).

\section{DSEI-MA: 1999-2000}

$O$ relacionamento da equipe de docentes da UFMA com a ESAI da FUNASA/CR-MA, que constituiu a chefia e a "equipe de apoio" do DSEI-MA, interrompeu-se após a realização do seminário em São Luís.

(4) Cf. UNIVERSIDADE FEDERAL DO MARANHÃO/CENTRO DE CIÊNCIAS DA SAÚDE/MESTRADO EM SAÚDE E AMBIENTE. Distrito Sanitário dos Povos Indígenas do Maranhão: projeto de implantação. São Luís: UFMA/CCS/MAS, 1999. Mimeo.

(5) REPRESENTANTES INDÍGENAS. A saúde dos povos indígenas. Pedido de anulação. São Luís, [s. d.]. Mimeo. 
Em 28 de agosto de 1999, o Decreto n. 3.156 da Presidência da República, formalizou e detalhou a estrutura e a inserção dos DSEls no âmbito das Coordenações Regionais da FUNASA

Como o Conselho Indigenista Missionário (CIMI) - que ainda era, na época, a organização não governamental (ONG) do Maranhão com alguma interlocução nesse campo da saúde indígena - por decisão nacional, recusou-se a estabelecer convênios para execução das ações do DSEls, por também discordar do modo como foram implantados, o recém-criado Departamento de Saúde Indígena (DESAI) da FUNASA (em Brasília) optou, no Maranhão, pela adoção das estratégias, práticas e alianças políticas anteriores da própria ESAI - e, portanto, da equipe da FUNAI/ADR-São Luís, ao invés da ampliação e aprofundamento da interlocução com a UFMA (o que exigiria rever as estratégias e metodologias até então adotadas).

Criaram-se 5 pólos-base no estado, com sedes em Arame, Amarante, Barra do Corda, Grajaú e Zé Doca, e em dezembro de 1999 foram pactuados convênios da FUNASA/CR-MA que tinham como objeto "prestar assistência integral à saúde das populações indígenas", com as Prefeituras de Amarante $(R \$ 1.145 .117,70)$, Arame $(R \$ 1.201 .617,21)$, Barra do Corda $(R \$$

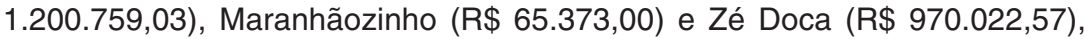
totalizando um investimento inicial de $R \$ 4.582 .889,51$ em convênios.

A exemplo de boa parte dos demais DSEls do país, o DSEI-MA já foi implantado sem capacidade técnica para acompanhamento dos convênios, uma vez que seus quadros profissionais também foram sendo transferidos para a Secretaria de Estado da Saúde do Maranhão (SES-MA) e municípios. As unidades gestoras dos subdistritos de endemias e das unidades de saúde da FUNASA foram extintas, e até o final de 1999, a FUNASA já havia consolidado a descentralização das ações de saúde aos municípios.

A contratação de recursos humanos para assistência à saúde foi realizada mediante convênios e/ou pelos municípios, por meio da descentralização orçamentária "fundo a fundo" do Ministério da Saúde/Secretaria de Assistência à Saúde (SAS), para o Fundo Municipal de Saúde dos municípios credenciados. Todas as contratações foram de caráter temporário.

Diante da precariedade dos dados de saúde disponíveis sobre comunidades indígenas (parciais, não globais, e dispersos entre as instituições atuantes em área), em grande parte dos DSEls implantados, a FUNASA criou o SIASI (Sistema de Informação da Atenção à Saúde Indígena) em 1999.

\section{DSEI-MA: 2000-2005}

Em 2000, a FUNASA formalizou, em Grajaú, o primeiro credenciamento, no Maranhão, de hospital para receber na modalidade "fundo a fundo" o 
Incentivo de Assistência Hospitalar e Apoio Diagnóstico à População Indígena (IAPI). O município dispunha do hospital filantrópico Hospital São Francis$c o$, que tradicionalmente vinha servindo de referência para as comunidades indígenas da região. Porém, este foi preterido pela Chefia do DSEI-MA e do DESAI, que optou pelo Hospital Santa Neusa, particular (ainda hoje contemplado com o maior montante, no estado, de recursos deste tipo repassados a hospitais: $\mathrm{R} \$ 35.000,00$ mensais) - transgredindo flagrantemente o disposto no art. 25 da Lei n. 8.080, de 19 de setembro de 1990 (Capítulo II — Da Participação Complementar) ${ }^{(6)}$.

Problemas e crises multiplicaram-se por quase todos os pólos-base do DSEI-MA, ao longo de 2000, resultando, além dos episódios de cativeiro e maus-tratos às equipes de campo, na apreensão, pelos índios, de vários veículos da FUNASA, o que culminou na destituição da Chefe do DSEI-MA, em fins de 2000.

Em julho de 2000, colhemos, em Imperatriz, os depoimentos de 4 dos 5 profissionais demissionários do pólo-base de Amarante. Optamos por transcrever na íntegra e descrever, abaixo, um dos trechos desta entrevista, que expõe detalhes do autoritarismo e desmandos, tanto da chefia do pólo-base de Amarante, como da chefia do próprio DSEI-MA e também das práticas indigenistas adotadas e cultivadas, sobretudo no que se refere ao modo como os dirigentes do DSEI-MA deveriam se posicionar no próprio relacionamento com os índios (posição que propunham fosse adotada na prática pelas equipes dos pólos-base):

- (L.) “(....) Então a gente se calava ... e aceitava do jeito que [citando o nome da então Chefe do pólo-base de Amarante] queria ... Sabe, porque ... o que eles passaram pra gente é que índio não tem voz nem vez ... foi isso que passaram ..."

- (entrevistador) "Isso foi dito... assim mesmo?..."

- (L.) "Isso foi dito ... foi passado ... que eles não tinham nem voz e nem vez."

- (entrevistador) "Mas quem disse isso?"

- (L.) "Não, eu não vou dizer quem disse isso."

- (A. M.) [passando a mão na cabeça de L.] "mãozinha na cabeça..."

(6) "Art. 24. Quando as suas disponibilidades forem insuficientes para garantir a cobertura assistencial à população de uma determinada área, o Sistema Único de Saúde (SUS) poderá recorrer aos serviços ofertados pela iniciativa privada.

Parágrafo único. A participação complementar dos serviços privados será formalizada mediante contrato ou convênio, observadas, a respeito, as normas de direito público.

"Art. 25. Na hipótese do artigo anterior, as entidades filantrópicas e as sem fins lucrativos terão preferência para participar do Sistema Único de Saúde (SUS)." 
- (L.) "Mas ... é ... era só um carinho ... era só você chegar, passar a mão no índio ... [passa a mão na cabeça de A. M.] dar um carinho pra ele ... e acabou. Nada mais. Então isso, eu acho que você ia embromando ... ia levando ... e o dinheiro ia caindo ...e eles iam passando, o tempo do convênio." (7)

A carga, no entanto, das cobranças e da insatisfação dos índios, e de seus confrontos com a política do DSEI-MA, como quase sempre ocorre nos serviços de saúde, não recaiu imediatamente sobre seus dirigentes, nem sobre os responsáveis pela política de saúde indígena da FUNASA, mas sobre as equipes de campo - que, não raro, nem concordavam com elas. Foram vários os episódios de profissionais e mesmo equipes de saúde que ficaram "presas" nas aldeias (proibidas pelos índios de deixá-las, por vezes amarradas literalmente, nos episódios mais graves, como no da Terra Indígena Caru, após a morte do filho de liderança local por tétano neonatal ${ }^{8}$ ):

- (E.) “... Infelizmente, quem sofre com isso são os índios, eles têm de reivindicar mesmo, porque, se ... eles não aprenderem a cuidar deles mesmos, coitados, vão ... infelizmente, vão continuar sempre assim. Eu fiquei presa na aldeia, mais ou menos, um dia e meio, por aí assim ... e ... eles exigiam de mim uma resposta, porque que eu estava saindo ... porque é que eu tinha me demitido ... e eu devo isso a eles... Na época eu... eu não podia falar, ali, exatamente o verdadeiro motivo porque é que eu tava saindo, porque ... poderia gerar um conflito maior ..."

- (L.) "um conflito ..."(9)

A equipe de Amarante, no entanto, foi daquelas que optou por romper, por não aceitar mais esse estado de coisas na FUNASA (note-se a referência a uma ética e interesses superiores ao do salário e do vínculo empregatício):

- (L.) "Então foi mais por isso ... foi mais por isso ... pela falta de humanidade mesmo ... é ... com eles, em relação a eles, que a gente resolveu se demitir. E a gente não ia se fazer cúmplice disso. Por isso saímos todo mundo. E eles pediram a nossa explicação, e foi até bom, que hoje a gente possa falar com calma, o que realmente a gente sente ... 0

(7) Entrevista (gravada em vídeo) com os profissionais que se demitiram do pólo-base do DSEI-MA da FUNASA em Amarante, realizada em Imperatriz/MA, aos 27.7.2000. In: VARGA, István van Deursen. Pelas fronteiras e trincheiras do indigenismo e do sanitarismo: a atenção às DST em comunidades indígenas, no contexto das políticas e práticas indigenistas e de saúde, na PréAmazônia. 2002. Tese (Doutorado) — Faculdade de Saúde Pública, Universidade de São Paulo, São Paulo, 2002. p. 300-302.

(8) Doença imunoprevenível, cuja vacina está inserida entre as obrigatórias; prova inequívoca de falha da cobertura vacinal básica daquela comunidade pela FUNASA.

(9) Entrevista (gravada em vídeo) com os profissionais que se demitiram do pólo-base do DSEI-MA da FUNASA em Amarante, realizada em Imperatriz/MA, aos 27.7.2000. In: VARGA, István van Deursen. Pelas fronteiras e trincheiras do indigenismo e do sanitarismo, cit., p. 300-302. 
que realmente ... e estar tendo a oportunidade de falar pra eles ... que ... não tem nada a ver com eles ... que ... infelizmente ... eles tão tendo uma coordenação ... falsa ... vamos dizer assim ..."(10)

A partir de 2001, as Prefeituras de Amarante do Maranhão, Barra do Corda, Imperatriz, Santa Inês, São Luís e Montes Altos foram contempladas com o incentivo hospitalar da FUNASA para atendimento à população indígena, e as de Amarante, Fernando Falcão, Arame, Jenipapo dos Vieiras e Grajaú foram credenciadas pela FUNASA para o recebimento de recurso "fundo a fundo" do Ministério da Saúde, denominado "Incentivo de Atenção Básica dos Povos Indígenas", para contratação de equipes multidisciplinares de atenção à saúde indígena.

Ainda em 2001, também foram pactuados convênios com as seguintes Associações Indígenas:

- Associação Indígena de Grajaú (ASSINGRA): R\$ 970.022,57: responsável pelas as ações de saúde a serem desenvolvidas na região indígena do município de Grajaú-MA; a ASSINGRA também firmou com a FUNASA convênio de saneamento com o objetivo de implantar sistemas de abastecimento de água ( $R$ \$ 709.491,42);

- Associação Indígena Kaneguatim: R\$ 956.277,00: responsável pelas as ações de saúde indígena a serem desenvolvidas no município de Barra do Corda.

Além da ausência de estrutura interna na FUNASA para monitoramento das ações desenvolvidas pelas equipes e pelos hospitais, tampouco o Ministério da Saúde realizou qualquer acompanhamento das ações desenvolvidas ou fiscalizou o uso efetivo dos recursos dos Incentivos.

Em 2002, eclodiram conflitos internos na ASSINGRA e na Kaneguatim, com dissidências descontentes com a atuação destas associações na prestação de serviços de saúde. Em decorrência, foram criadas mais 7 associações indígenas que também firmaram convênios com a FUNASA. No total, durante o ano de 2002, foram disponibilizados, para o DSEI-MA, mediante convênios, um total de $R \$ 8.390 .159,77$. Estes convênios não contiveram, no entanto, as dissidências e conflitos, sobretudo entre os Guajajaras; ao contrário, os estimularam. Neste ano, a FUNASA/CR-MA firmou convênio com uma ONG não-indígena, o Instituto de Cooperação Pró-Vida, para atender a área indígena do pólo-base de Zé Doca e as Casas de Saúde Indígena (CASAls) de Imperatriz e São Luís.

Diversas CASAls forma criadas, em 2002, em Barra do Corda, Arame e Grajaú, para atender os indígenas que fazem parte das associações conveniadas e os chamados dissidentes.

(10) Id. Ibid. 
Ainda em 2002, foi realizado, finalmente, o $1^{\circ}$ Treinamento (Módulo I) para os Agentes Indígenas de Saúde.

As dissidências nas associações indígenas intensificaram-se ao longo de 2003, e com o acúmulo de seus débitos nas praças, a FUNASA/CR-MA viu-se obrigada a atender diretamente essa população.

Observou-se, em 2003, aumento considerável nos recursos disponibilizados aos municípios para contratação de profissionais para a saúde indígena (o Maranhão esteve, neste ano, entre os estados que mais receberam recursos dessa origem).

Por outro lado, já em 2003 manifestou-se forte tendência à concentração do atendimento médico e de enfermagem nas sedes dos municípios, diversas terras indígenas não foram contempladas por nenhuma etapa vacinal e a Organização Pró-Vida foi denunciada por mal uso dos recursos públicos e por nepotismo.

Em outubro de 2003, a sede da FUNASA/CR-MA foi ocupada por índios que reivindicavam melhorias no atendimento à saúde. Na ocasião, foi firmado um Termo de Ajustamento de Conduta entre a FUNASA/CR-MA, lideranças indígenas e o Ministério Público Federal (com 13 cláusulas) e, em novembro de 2003, realizou-se uma reunião do Conselho Distrital do DSEI-MA.

Ao longo de 2004, observou-se que nenhuma cláusula do Termo de Ajustamento e Conduta foi obedecida e que todos os convênios de assistência à saúde foram encerrados, com a FUNASA assumindo diretamente a execução das ações de assistência à saúde a indígenas. Não foi realizado, entretanto, planejamento das ações para a transição dos convênios à administração direta, o que proporcionou um maior acúmulo de débitos nos municípios, pela inexistência de contratos específicos que suprissem as despesas correntes. O ano transcorreu com diversas denúncias, pelos índios, da má qualidade da assistência prestada no DSEI-MA.

Apesar das deficiências identificadas na geração de dados de saúde, alguns dados de morbimortalidade foram divulgados pela FUNASA neste ano. A taxa de mortalidade infantil, entre os anos de 1999 a 2004, apresentou um incremento de $24 \%$ dentro do período e um comportamento crescente entre os anos. Essa informação sugere dúvidas, no entanto, tendo em vista as dificuldades de operacionalização do SIASI e a carência de uma organização de serviços que garanta a presença da equipe de saúde efetivamente nas aldeias, sendo provável que muitas das notificações de mortalidade não foram incluídas no sistema, mesmo diante do incremento de notificações identificadas.

Tabela 1.1 — Taxas de mortalidade infantil do DSEI-Maranhão, 1999-2004.

\begin{tabular}{|l|c|c|c|c|c|l|}
\hline Ano & 1999 & 2000 & 2001 & 2002 & 2003 & 2004 \\
\hline Taxa de mortalidade infantil & $\begin{array}{c}\text { Não } \\
\text { informada }\end{array}$ & 13,46 & 38,25 & 12,03 & 35,55 & 54,90 \\
\hline
\end{tabular}

Fonte: FUNASA/SIASI: http://sis.funasa.gov.br/siasi, em 16.12.04. 
O Coordenador Regional da FUNASA CR-MA acumulou o cargo de Chefe do DSEI e Coordenador por quase todo o ano de 2004.

Entre 2004 e 2005, nenhuma etapa vacinal foi realizada no DSEI-MA, extraviaram-se as informações consolidadas (registros manuais) de morbidade e mortalidade, e registrou-se aumento significativo de débitos para atender as despesas do DSEI-MA.

Finalmente, em dezembro de 2005, foi firmado convênio com a ONG Missão Evangélica Kaiowa, de Mato Grosso do Sul, para operacionalização das ações no âmbito do DSEI-MA.

\section{IV CONFERÊNCIA NACIONAL DE SAÚDE INDÍGENA (2006): POVOS E COMUNIDADES INDÍGENAS DO MARANHÃO TENTAM A RETOMADA DO CONTROLE SOCIAL DA POLÍTICA DE SAÚDE(11)}

Conforme estabelecido no Regimento da IV Conferência Nacional de Saúde Indígena (aprovado na 155 Nacional de Saúde, realizada aos 8 e 9 de junho de 2005), suas etapas locais deveriam ter sido realizadas até 30 de outubro de 2005 e suas etapas distritais, até 31 de dezembro de 2005.

Foram vários os problemas na realização das etapas locais e distritais da IV Conferência Nacional de Saúde Indígena, entre povos e comunidades indígenas abrangidos por vários DSEls.

No Maranhão, essas Conferências Locais simplesmente não foram realizadas, o que motivou representantes indígenas e da UFMA a fazerem uma série de contatos com a Comissão Organizadora, em Brasília, por telefone, e-mail e pessoalmente.

As instruções repassadas por membro da Comissão Organizadora, em reunião realizada com representante do MSA/UFMA, em 14 de novembro de 2005, na sede do DESAI (em Brasília/DF), foram de que todos os problemas no processo de realização das etapas preparatórias do evento, no âmbito do DSEI-MA, deveriam ser encaminhados a seu respectivo Conselho Distrital. Ora, como fazê-lo, se este não se reuniu uma única vez, ao longo de 2005? Diante deste contra-argumento, o referido membro da Comissão Organizadora limitou-se a negar este fato, reiterando que o Conselho Distrital de Saúde Indígena do Maranhão estava, sim, funcionante (no que seria flagrantemente desmentido, posteriormente, pelos próprios membros deste Conselho

(11) ASSOCIAÇÃO NACIONAL DE AÇÃO INDIGENISTA (ANAÍ), CONSELHO INDIGENISTA MISSIONÁRIO (CIMI), MESTRADO EM SAÚDE E AMBIENTE/UNIVERSIDADE FEDERAL DO MARANHÃO (MSA/ UFMA). Nota pública sobre a IV Conferência Nacional de Saúde Indígena. São Luís, 7 de abril de 2006. 
Distrital de Saúde Indígena, durante a II Conferência Distrital de Saúde do Maranhão, realizada de 22 a 24 de março de 2006).

Esta situação motivou o MSA/UFMA a protocolar uma representação contra a FUNASA, junto à Procuradoria da República no Maranhão, em 11 de janeiro de 2006, solicitando: a) que fosse assegurada a realização, no estado, de todas as etapas preparatórias previstas (locais e distrital) da IV Conferência Nacional de Saúde dos Povos Indígenas; b) que fosse postergada a realização da etapa nacional da IV Conferência, de modo a assegurar prazo hábil para que a todas as comunidades indígenas no Maranhão fosse garantida ampla, ativa e representativa participação em todas as etapas do evento, em igualdade de condições com as comunidades abrangidas pelos demais DSEls da Federação.

À revelia da não-realização de suas etapas locais, e de todas as demandas e protestos encaminhados à Comissão Organizadora da IV Conferência, a FUNASA anunciou que realizaria a II Conferência Distrital de Saúde Indígena do MA de 6 a 8 de fevereiro de 2006.

Em 7 de fevereiro de 2006, índios Krikati, Gavião, Awa-Guajá e Guajajara bloquearam a Ferrovia Carajás em seu km 289, entre os povoados de Poeira e Três Bocas, no município de Alto Alegre do Pindaré, em protesto contra a FUNASA (que anunciava já estar realizando, naqueles dias, a II Conferência Distrital de Saúde Indígena do MA). Entre as reivindicações estavam: a exoneração do Coordenador Regional da FUNASA; a autonomia política, administrativa e orçamentária para o DSEI-MA; a criação de mais 2 DSEls no MA; a anulação da II Conferência Distrital de Saúde Indígena, pretensamente realizada em São Luís e a rescisão do contrato com a Missão Kaiowa para atendimento à saúde indígena no Maranhão.

Na seqüência, a Coordenação das Articulações dos Povos Indígenas no Maranhão (COAPIMA) e a Associação dos Povos Indígenas do Grajaú (ASSINGRA) entraram com representação junto ao Ministério Público Federal, solicitando a anulação da Conferência realizada pela FUNASA, entre os dias 6 e 8 de fevereiro, e a organização de um novo evento.

Essa mobilização dos índios foi bem-sucedida em vários aspectos, tendo obtido a demissão, em fevereiro, de Zenildo Oliveira do cargo de Coordenador Regional da FUNASA no MA e o reconhecimento, por parte da instituição, de nova Conferência Distrital de Saúde Indígena do MA, a realizar-se de 22 a 24 de março de 2006, em São Luís.

Paralelamente, a representação movida pelo Ministério Público Federal resultou em liminar da Justiça Federal, anulando a Conferência Distrital realizada pela FUNASA, de 6 a 8 de fevereiro.

Assim que os índios retiraram-se da ferrovia, entretanto, a FUNASA tornou a acionar seus prepostos de plantão para reverter vários dos compro- 
missos assumidos pela instituição, quando da negociação com os índios na ferrovia, entre eles o da rescisão do contrato com a Missão Kaiowa e o da anulação da Conferência Distrital por ela realizada em fevereiro (um agravo movido pela FUNASA contra a liminar concedida pela Justiça Federal conseguiria derrubá-la em 27 de março, véspera do início da Conferência).

O Regimento e o Regulamento da etapa nacional da IV Conferência estabeleceram regras que engessaram uma programação de atividades já pré-definida e extensa, restringiram o acesso dos delegados às Plenárias Temáticas e complicaram a condução das mesas e votações.

A cada delegado só foi permitida a participação efetiva (com direito a voto) em apenas uma das Plenárias Temáticas, por meio de inscrição prévia, registrada no "sistema" (os bancos de dados da Comissão Organizadora) e impressa em seu crachá.

Muitos delegados tiveram sua inscrição remanejada "pelo sistema", contra sua vontade, para outras Plenárias Temáticas, em função de ter "estourado" a cota pré-definida para sua respectiva categoria de representação ("usuário", "trabalhador indígena de saúde", "trabalhador não-indígena de saúde", "governo", "prestador de serviço") na Plenária Temática de sua escolha.

Além das sucessivas ações anteriores da FUNASA e da Comissão Organizadora para impugnar a legítima II Conferência Distrital, reconhecida pelos índios (realizada de 22 a 24 de março), já durante a etapa nacional, a delegação do Maranhão teve novamente que se mobilizar para enfrentar as conseqüências do encaminhamento inicial, por parte da mesma Comissão Organizadora, de seu pleito pelo reconhecimento da Plenária, instalada em 28 de março. Inicialmente, reprovado (porque mal explicado), o pleito teve de ser reconduzido à Plenária, quando foi reconhecido, por votação unânime.

Em decorrência deste encaminhamento inicial do pleito da delegação do Maranhão, esta foi tardiamente credenciada, e seus delegados foram distribuídos aleatoriamente, "pelo sistema", entre as diversas Plenárias Temáticas.

Ainda, os delegados do Maranhão foram informados que as propostas aprovadas na II Conferência Distrital do Maranhão não poderiam ser apreciadas, discutidas e votadas em nenhuma das Plenárias Temáticas, por não terem sido encaminhadas a tempo de serem incorporadas ao caderno "Relatório consolidado das Distritais", distribuído pela Comissão Organizadora. A única possibilidade de encaminhá-las no evento seria na forma de moções à Plenária Final.

Outro dispositivo do Regulamento estabeleceu também que apenas as moções com no mínimo 96 assinaturas poderiam ser encaminhadas à 
Plenária Final. Em tão curto espaço de tempo não foi possível conseguir o número mínimo de assinaturas para nenhuma das moções elaboradas pela delegação do Maranhão, contendo propostas da II Conferência Distrital de Saúde Indígena do Maranhão.

Além dos problemas na instalação e no andamento das Plenárias Temáticas, acima descritos, o encaminhamento das propostas para votação na Plenária Final também foi problemático. À metodologia engessada adotada pelo Regulamento, somaram-se conduções de mesa burocráticas e ininteligíveis, que inviabilizaram um acompanhamento atento e participativo da maior parte dos presentes, especialmente dos delegados indígenas.

A votação mais conturbada da Plenária Final certamente foi a da questão da gestão da Política Nacional de Saúde Indígena, não apenas pela importância estratégica do assunto, mas, novamente, pela falta de clareza na condução da mesa. Vários dos delegados indígenas que votaram na proposta vitoriosa (a de que se mantivesse a FUNASA como gestora) protestariam publicamente contra a confusa coordenação daquela mesa de votação, que os teria induzido a irem contra a proposta que na realidade defendiam.

A delegação do DSEI-Xingu, em protesto, anunciou sua retirada da Plenária Final, que começou, a partir de então, a dispersar-se.

Diante da insatisfação geral com o andamento dos trabalhos, começou a circular a proposta de impugnação da IV Conferência. Ainda com a Plenária Final em andamento, grande parte dos delegados indígenas retirou-se e, em reunião paralela, convocou o coordenador da mesa, repreendendo-o, assim como a toda a Comissão Organizadora, pela manipulação dos trabalhos. Estes delegados redigiram documento, subscrito por 27 dos 34 Presidentes de Conselhos Distritais presentes, além da COIAB e outras organizações indígenas, denunciando o processo e solicitando a impugnação da IV Conferência.

Os problemas no processo de realização da IV Conferência Nacional de Saúde Indígena comprometeram muito seriamente sua representatividade e a legitimidade de suas propostas, enquanto instância máxima propositiva da Política Nacional de Saúde Indígena, conforme disposto na Lei n. 8.142/90, e motivaram a Associação Nacional de Ação Indigenista (ANAÍ), o Conselho Indigenista Missionário (CIMI) e o Mestrado em Saúde e Ambiente da Universidade Federal do Maranhão (MSA/UFMA) a divulgarem, em 7 de abril de 2006, uma nota pública endossando o protesto e os termos do documento elaborado e subscrito, pela maioria dos Presidentes de Conselhos Distritais de Saúde Indígena e demais delegados indígenas presentes ${ }^{(12)}$.

(12) Associação Nacional de Ação Indigenista (ANAÍ), cit. 
Em dezembro de 2006, a Missão Evangélica Kaiowá retomou os trabaIhos no DSEI-MA, respaldada pelas várias lideranças indígenas que havia contratado, para dar andamento ao convênio firmado com a FUNASA.

\section{CONSIDERAÇÕES FINAIS E PROPOSTAS}

\section{Reterritorializar os DSEls no Maranhão}

1. Verifica-se no atual DSEI-MA, no que se refere à preparação de recursos humanos para atuação em contexto intercultural:

- a inexistência de uma política de recursos humanos para o trabalho, num contexto intercultural, que englobe uma formação permanente, como também um plano de carreira específico;

- os contratos temporários são uma das principais dificuldades para o investimento em uma formação permanente para o trabalho com populações indígenas;

— as ações desenvolvidas relativas à preparação de recursos humanos resumem-se a treinamentos para os profissionais enfermeiros e engenheiros que realizam, respectivamente, o treinamento dos Agentes Indígenas de Saúde (AIS) e o treinamento dos Agentes Indígenas de Saneamento (AISAN). Em razão da alta rotatividade de profissionais em área, a continuidade destes treinamentos, no entanto, ficou comprometida;

- nos conteúdos programáticos destes treinamentos observa-se a valorização do saber biomédico em detrimento do saber tradicional;

- ausência e/ou carência da participação das instituições de ensino e pesquisa na produção de conhecimentos e tecnologias adequadas para a solução dos problemas de interesse das comunidades e, também, para a construção de propostas e/ou programas especiais que facilitem a inserção de alunos de origem indígena.

2. No que se refere à articulação das práticas de trabalho do DSEI-MA com os saberes tradicionais indígenas, verifica-se a total inexistência de uma política de recursos humanos, o que se constitui num dos entraves principais para a adequação da garantia do acesso aos serviços prestados, com respeito às especificidades culturais e o reconhecimento dos saberes tradicionais.

3. No que se refere ao monitoramento das ações no âmbito do DSEIMA, verifica-se:

- carência de capacidade técnica na FUNASA/CR-MA para o monitoramento das ações desenvolvidas em área indígenas; 
- carência e/ou ausência de dados de morbidade, mortalidade, produção de serviços, entre outros, para subsidiar seu planejamento, avaliação e gerenciamento;

- a carência de informações gera entraves na identificação das necessidades de cada nível gerencial, impedindo o fornecimento de subsídios para construção de indicadores que avaliem a atenção à saúde, no que diz respeito ao acesso aos serviços, cobertura e efetividade, como também, à identificação de riscos e das condições especiais no processo de adoecer;

- o modelo assistencial implantado está direcionado para o atendimento da demanda espontânea.

4. No que se refere à promoção de ações específicas em situações especiais, as ações realizadas no DSEI-MA (assim como em boa parte dos demais 33 DSEIs) ainda não contemplam as seguintes situações:

- prevenção e controle de agravos à saúde em povos com pouco contato ou "isolados";

- prevenção e controle de agravos à saúde nas regiões de fronteira, em articulação com as instituições nacionais e cooperação técnica com os países vizinhos;

- realização de estudos específicos de impactos na saúde e suas repercussões no campo social, voltados a populações e comunidades indígenas em áreas de influência de grandes projetos de desenvolvimento;

- acompanhamento, monitoramento e desenvolvimento de ações que venham coibir agravos de violência (suicídios, agressões e homicídios, alcoolismo) em decorrência das condições de vida e da expropriação e intrusão das terras indígenas;

- prevenção e assistência em doenças sexualmente transmissíveis e AIDS, priorizando a capacitação de multiplicadores dos agentes indígenas de saúde;

— implantação de programas de segurança alimentar para os povos e comunidades indígenas.

Desde 1999, o DSEI-MA vem sendo apontado como um dos mais problemáticos e de pior desempenho no país, o que, em grande medida, explica-se pela transgressão, em sua implantação, de princípios e diretrizes fundamentais para esse processo, definidos pela legislação vigente e pelas Conferências Nacionais de Saúde (cf. VARGA, 2002). Como nos anos anteriores, entre 2003 e 2006, vários funcionários e veículos da FUNASA foram retidos em comunidades indígenas, como forma de protesto contra a má qualidade e a descontinuidade de seus serviços. 
No que se refere ao controle social, o Conselho Distrital do DSEI-MA, criado em 1999, também apresenta-se como um dos de pior desempenho entre os demais DSEls no país. Para comprovar esta afirmação, basta considerar-se que:

- realizou um total de apenas 7 reuniões, de 1999 até a 2008, numa média de menos de uma reunião por ano;

- uma das queixas mais freqüentes das comunidades indígenas do Maranhão, em relação à dinâmica de reuniões imposta pela primeira Chefia do DSEI-MA aos Conselhos Locais de Saúde Indígena, é de que apenas conselheiros e agentes de saúde (a quase totalidade de jovens) têm tido direito à voz em suas reuniões, de modo que os mais velhos e as lideranças tradicionais têm sido alijadas;

- no processo de implantação do DSEI-MA, a primeira gestão (1999-2001) de sua Chefia, desconsiderando diversidades étnicas e sociais e núcleos indígenas tradicionais de organização e/ou poder, criou cinco "pólos-base" e seus respectivos Conselhos Locais de Saúde Indígena;

- a primeira gestão da Chefia do DSEI-MA promoveu ações para deslegitimar organizações indígenas já anteriormente existentes (chegando a constranger e ameaçar alguns de seus membros). É o caso do Conselho de Saúde Indígena de Arame (CSIA), criado em outubro de 1998 (antes da implantação do DSEI-MA, portanto) por lideranças Guajajaras com experiência acumulada em movimentos sociais e em Conferências de Saúde Indígena - motivo por que o CSIA passou a ser a organização indígena com maior poder de crítica organizada ao processo de implantação do DSEI-MA (cf. Varga, 2002).

Os 5 pólos-base e respectivos Conselhos Locais de Saúde Indígena, criados na primeira gestão da Chefia do DSEI-MA, apresentaram péssimo desempenho, tanto no que se refere à qualidade da atenção à saúde prestada, como à organização e periodicidade de reuniões de seus Conselhos Locais de Saúde Indígena. Estes 5 pólos-base e conselhos, entre 2000 e 2006 subdividiram-se, na prática (pelos próprios índios), em outros dezenove: o de Amarante subdividiu-se em 4, o de Arame em 4, o de Grajaú em 4, o de Barra do Corda em 5, e o de Zé Doca em 2.

A própria mobilização dos índios do Maranhão, no processo de preparação da IV Conferência Nacional de Saúde Indígena estabeleceu, como uma de suas principais metas e reivindicações, a subdivisão do território do atual DSEI-MA em pelo menos três novos DSEls.

Os panoramas ambiental e socioeconômico e as políticas públicas mudaram muito, no Maranhão, ao longo dos sete anos de existência do DSEI-MA, determinando novas e intensas pressões e investidas das frentes 
de expansão do capital sobre os territórios indígenas ${ }^{(13)}$, acarretando-lhes graves danos ambientais (como o assoreamento e seca do rio Buriticupu, o único ainda perene da Terra Indígena Araribóia) e impactos sobre sua saúde e qualidade de vida, cujo diagnóstico atualizado é de grande importância para o urgentemente necessário processo de reterritorialização dos DSEls no Maranhão.

\section{REFERÊNCIAS BIBLIOGRÁFICAS}

ASSOCIAÇÃO NACIONAL DE AÇÃO INDIGENISTA (ANAÍ), CONSELHO INDIGENISTA MISSIONÁRIO (CIMI), MESTRADO EM SAÚDE E AMBIENTE/ UNIVERSIDADE FEDERAL DO MARANHÃO (MSA/UFMA). Nota pública sobre a IV Conferência Nacional de Saúde Indígena. São Luís, 7 de abril de 2006.

FUNDAÇÃO NACIONAL DE SAÚDE/COORDENAÇÃO REGIONAL DO MARANHÃO. Distrito Sanitário Especial Indígena do Maranhão. São Luís, 1999. Mimeo.

FUNDAÇÃO NACIONAL DE SAÚDE/SIASI. Tabela 1.1 - Taxas de mortalidade infantil do DSEI-Maranhão, 1999-2004. Disponível em: <http:// sis.funasa.gov.br/siasi>. Acesso em: 16 dez. 2004.

REPRESENTANTES INDÍGENAS. A saúde dos povos indígenas. Pedido de anulação. São Luís, [s.d.]. Mimeo.

UNIVERSIDADE FEDERAL DO MARANHÃO/CENTRO DE CIÊNCIAS DA SAÚDE/MESTRADO EM SAÚDE E AMBIENTE. Distrito Sanitário dos Povos Indígenas do Maranhão: projeto de implantação. São Luís: UFMA/CCS/MAS, 1999. Mimeo.

VARGA, István van Deursen. Educação em saúde: ideologias, racionalidades, discursos e práticas institucionais em 15 anos de indigenismo (Brasil, anos 1980-1995). In: ASSIS, E. (Org.). Educação Indígena na Amazônia: experiências e perspectivas. Belém: Associação de Universidades Amazônicas; Universidade Federal do Pará, 1996. p. 229-269.

Pelas fronteiras e trincheiras do indigenismo e do sanitarismo: a atenção às DST em comunidades indígenas, no contexto das políticas e práticas indigenistas e de saúde, na Pré-Amazônia. 2002. Tese (Doutorado) - Faculdade de Saúde Pública, Universidade de São Paulo, São Paulo, 2002.

(13) Categoria que abrange as de Terras Indígenas já demarcadas e os demais territórios de seu uso, mesmo que não demarcados. 